\title{
Validation of COSMIC ionospheric peak parameters by the measurements of an ionosonde chain in China
}

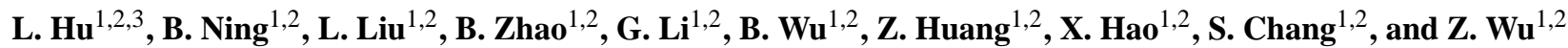 \\ ${ }^{1}$ Key Laboratory of Earth and Planetary Physics, Institute of Geology and Geophysics, Chinese Academy of Sciences, \\ Beijing, China \\ ${ }^{2}$ Beijing National Observatory of Space Environment, Institute of Geology and Geophysics, Chinese Academy of Sciences, \\ Beijing, China \\ ${ }^{3}$ University of Chinese Academy of Sciences, Beijing, China
}

Correspondence to: L. Hu (hulh@mail.iggcas.ac.cn)

Received: 3 July 2014 - Revised: 10 September 2014 - Accepted: 19 September 2014 - Published: 28 October 2014

\begin{abstract}
Although the electron density profiles (EDPs) from Constellation Observing System for Meteorology, Ionosphere, and Climate (COSMIC) measurement have been validated by ionosonde data at a number of locations during the solar minimum period, the performance of COSMIC measurements at different latitudes has not been well evaluated, particularly during the solar maximum period. In this paper the COSMIC ionospheric peak parameters (peak electron density of the F region $-N m \mathrm{~F} 2$; peak height of the F region - hmF2) are validated by the ionosonde data from an observation chain in China during the solar maximum period of 2011-2013. The validations show that the COSMIC measurement generally agrees well with the ionosonde observation. The error in NmF2 from COSMIC and ionosonde measurements varies with latitude. At midlatitude stations, the differences between COSMIC $N m \mathrm{~F} 2 \mathrm{~s}$ and those of ionosondes are very slight. However, COSMIC $N m$ F2 overestimates (underestimates) that of the ionosonde at the north (south) of the equatorial ionization anomaly (EIA) crest. The relative errors of $h m \mathrm{~F} 2 \mathrm{~s}$ are much lower than those of $N m \mathrm{~F} 2 \mathrm{~s}$ at all stations, which indicates the EDP retrieval algorithm of the COSMIC measurement has a better performance in determining the ionospheric peak height. The root mean square errors (RMSEs) of $N m \mathrm{~F} 2 \mathrm{~s}(h m \mathrm{~F} 2 \mathrm{~s})$ are higher (lower) during the daytime than during the nighttime at all stations. Correlation analysis shows that the correlations for both $\mathrm{NmF} 2 \mathrm{~s}$ and $h m \mathrm{~F} 2 \mathrm{~s}$ are comparably good (correlation coefficients $>0.9$ ) at midlatitude stations, while correlations of $\mathrm{NmF} 2$ (correlation coefficients $>0.9$ ) are higher than those of $h m \mathrm{~F} 2$ (correlation coefficients $>0.8$ ) at low-latitude stations.
\end{abstract}

\section{Introduction}

Since the radio occultation (RO) technique using the GPS signals was first employed by the Global Positioning System Meteorology (GPS/MET) experiment aboard the Microlab1 satellite in 1995, the low-earth-orbit-based GPS RO technique has proven successful in exploring the earth's lower atmosphere and ionosphere. The RO data provide vertical profiles of neutral density, temperature, pressure and water vapor in the stratosphere and troposphere and electron density in the ionosphere (Hajj and Romans, 1998; Rocken et al., 2000; Schreiner et al., 1999), and they have been widely used in atmosphere and ionosphere research, as well as weather and space weather forecasting (Krankowski et al., 2011; Wickert et al., 2009).

A constellation of six microsatellites, termed the FORMOSAT-3/COSMIC (Formasa Satellite 3 - Constellation Observing System for Meteorology, Ionosphere, and Climate) was launched into a low earth orbit at around $800 \mathrm{~km}$ in 2006. Each microsatellite carries a GPS occultation experiment payload to operate the RO measurement. Owing to the multi-satellite configuration, the COSMIC constellation can provide much more vertical electron density profiles (EDPs) than previous missions. The availability of COSMIC EDP data significantly enlarges the database for a variety of ionospheric research on a global scale, such as research into the variation of ionospheric peak parameters and scale heights (L. Liu et al., 2008, 2009, 2010, 2011), storm time ionospheric behavior (Zakharenkova et al., 2012) and low-latitude F3 layer occurrence (Zhao et al., 2011).

Keywords. Ionosphere (equatorial ionosphere) 
The COSMIC ionospheric EDPs are retrieved from the RO data by the Abel inversion under the assumption of ionospheric symmetry (Lei et al., 2007). Statistical comparisons of ionospheric peak parameters $(\mathrm{NmF} 2$ and $h m \mathrm{~F} 2)$ measured by COSMIC satellites and ionosondes indicate that there are considerable high correlations between COSMIC and ionosonde ionospheric parameters (Lei et al., 2007; Chu et al., 2010; Chuo et al., 2011, 2013; Ely et al., 2012; Krankowski et al., 2011; J.-Y. Liu et al., 2010; Hu et al., 2014). Comparisons of COSMIC-based EDPs with the data of incoherent scatter radar (ISR) at Millstone Hill, Jicamarca, Arecibo and Kharkov show that there is good agreement between the COSMIC and ISR EDPs (Lei et al., 2007; Kelley et al., 2009; Cherniak and Zakharenkova, 2014). Evaluations of COSMIC performance by simulations show that the $N m \mathrm{~F} 2$ and $h m \mathrm{~F} 2$ retrieved from COSMIC measurements are generally in good agreement with the "true values" calculated from the integrated total electron content (TEC) along the COSMIC occultation paths, with the "true" electron density taken from the NeQuick model, but the reliability of the retrieved electron density decreases in low-latitude regions and at low altitudes (Yue et al., 2010, 2011a, b).

According to the simulation results of Yue et al. (2010, 2011a, b), the Abel inverted electron density has systematic deviation because of the spherical symmetry assumption. The relative errors of COSMIC ionospheric parameters have significant geomagnetic latitude and local time dependency. However, latitude dependency of the performance of COSMIC measurements has not been well validated by groundbased observation. Most of the published validations by manually scaled ionosonde data focused on low-latitude regions, particularly during the solar minimum. Chu et al. (2010) carried out a global survey of COSMIC ionospheric peak parameters by comparing them with ground-based ionosonde data from the Space Weather Prediction Center (SWPC), NOAA. However, their results were restricted by the inhomogeneous distribution of the ionosonde stations. To deal with the abovementioned issues, a comparison of ionospheric peak parameters retrieved from COSMIC and a chain of ionosondes in China during the solar maximum (2011-2013) is made in this paper. Statistical analysis of diurnal variation, absolute and relative errors, and correlations of $N m \mathrm{~F} 2$ and $h m \mathrm{~F} 2$ are presented regarding the different latitudes.

\section{Data processing}

As a conventional technique for ionospheric observation, globally distributed ionosondes provide a large database for calibrating and validating other measurements. An observation chain consisting of four DPS4D ionosondes was set up during 2010 to early 2011 in China. As shown in Fig. 1 and Table 1, the four stations are located along the $120^{\circ} \mathrm{E}$ longitude, covering the geomagnetic midlatitude (Mohe and Beijing) and low-latitude (Wuhan and Sanya) regions with
Table 1. Coordinates of the ionosonde stations.

\begin{tabular}{lrrr}
\hline Station & $\begin{array}{r}\text { Geographic } \\
\text { longitude }\left({ }^{\circ} \mathrm{E}\right)\end{array}$ & $\begin{array}{r}\text { Geographic } \\
\text { latitude }\left({ }^{\circ} \mathrm{N}\right)\end{array}$ & $\begin{array}{r}\text { Geomagnetic } \\
\text { latitude }\left({ }^{\circ} \mathrm{N}\right)\end{array}$ \\
\hline Mohe & 122.3 & 53.5 & 43.5 \\
Beijing & 116.2 & 40.3 & 30.1 \\
Wuhan & 114.6 & 31.0 & 20.8 \\
Sanya & 109.6 & 18.3 & 8.1 \\
\hline
\end{tabular}

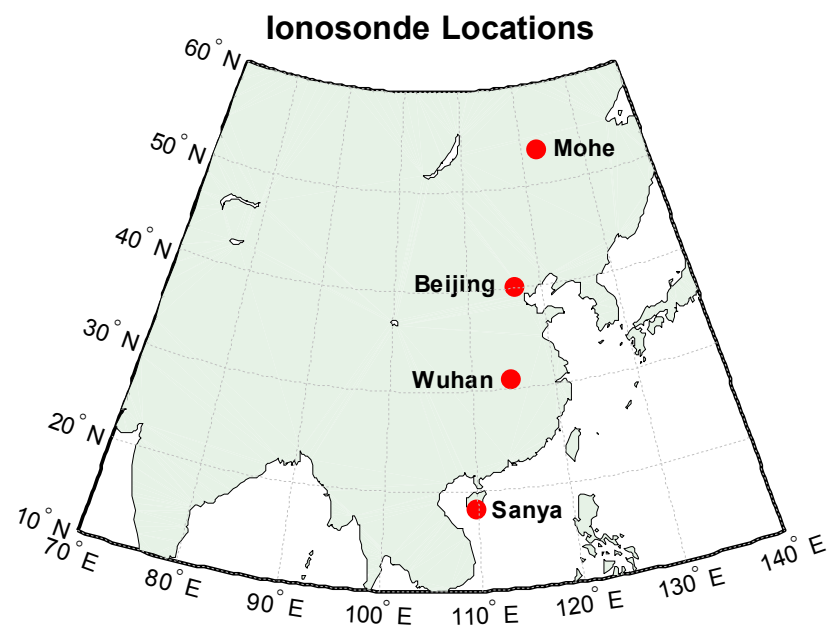

Figure 1. The ionosonde locations in the observation chain in China.

a sequential latitude difference of about $10^{\circ}$. All stations are equipped with DPS4D ionosondes performing a routine ionospheric vertical sounding every $15 \mathrm{~min}$ after installation.

The Digital Portable Sounder 4D (DPS4D) ionosonde developed by the University of Massachusetts Lowell is the most widely used one in the world, with the capability of precise ionospheric sounding and real-time data analysis (Reinisch and Galkin, 2011). The sounding data (ionograms) can be automatically scaled by ARTIST5 software with considerable reliability (Galkin and Reinisch, 2008). However, all the ionograms were manually scaled using the SAO Explorer software to ensure data accuracy. The ionograms with strong spread $\mathrm{F}$ or a rather weak trace were eliminated during the manual data checking step. The ionospheric EDP, $N m \mathrm{~F} 2$ and $h m \mathrm{~F} 2$ were then calculated by the true height inversion algorithm NHPC, embedded in the SAO Explorer software (Reinisch and Huang, 2001).

The COSMIC EDP data were obtained from the COSMIC Data Analysis and Archive Center (CDAAC) at the University Corporation for Atmospheric Research (UCAR). For comparison, the COSMIC EDPs in which the tangent point of the F layer peak was close to the four ionosonde stations, with a maximum difference of $2.5^{\circ}$ in latitude and longitude, were selected. Although the level 2 ionospheric profile data have been post-processed at CDAAC, we further fitted each individual EDP with a Chapman $\alpha$ function as described by 

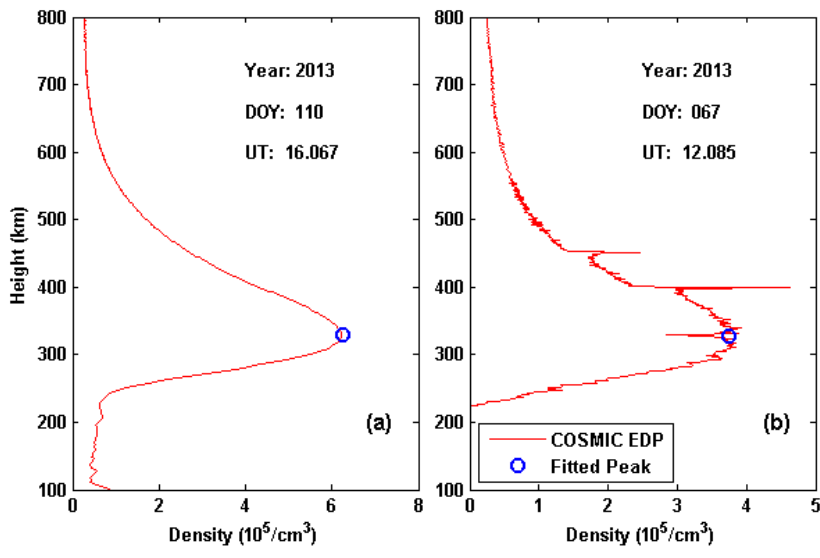

Figure 2. Samples of fitting the COSMIC EDP by Chapman $\alpha$ function. DOY stands for "day of year".

Liu et al. (2007) to obtain the $N m \mathrm{~F} 2$ and $h m \mathrm{~F} 2$ values. The fitting was limited to within the altitude of $160-600 \mathrm{~km}$ to avoid the larger error in electron density at lower altitudes (Kelley et al., 2009; Yue et al., 2010). As indicated by Fig. 2a, in most cases the COSMIC EDPs are very smooth and the fitted ionospheric peaks are just around the maximum position of electron density. However, in a few cases there exist spur structures within the profiles, and the ionospheric peaks can be retrieved reasonably well from the Chapman function fitting (Fig. 2b).

For individual RO events close to the ionosonde stations, corresponding ionosonde data with a time difference of less than $7.5 \mathrm{~min}$ were selected to form data pairs for comparison. The total numbers of data pairs are 583, 429, 343 and 502 for Mohe, Beijing, Wuhan and Sanya, respectively. The difference in the number of data pairs results from several factors, such as a lack of measurements during power shutdown and ionosonde maintenance, data rejection during manual ionogram scaling, and the nonuniform latitudinal distribution of COSMIC RO events.

\section{Results}

Figure 3 shows the diurnal variation of ionospheric peak parameters retrieved from COSMIC and ionosonde measurements at four stations. The hourly values of $N m \mathrm{~F} 2$ and $h m \mathrm{~F} 2$ were averaged from the selected data pairs with a time difference of less than $30 \mathrm{~min}$ from a given hour. The hourly root mean square errors (RMSEs) between peak parameters from the COSMIC and ionosondes measurements are also provided. It should be noted that a bias of 200 is added to the RMSE of $h m \mathrm{~F} 2 \mathrm{~s}$ in order to show all the data in the subfigure together. The result indicates that the COSMIC $N m \mathrm{~F} 2$ and $h m \mathrm{~F} 2$ generally follow the same trends of diurnal variation as those of the ionosondes at four stations. The $N m \mathrm{~F} 2 \mathrm{~s}$ of both measurements at all stations reach the minimum around
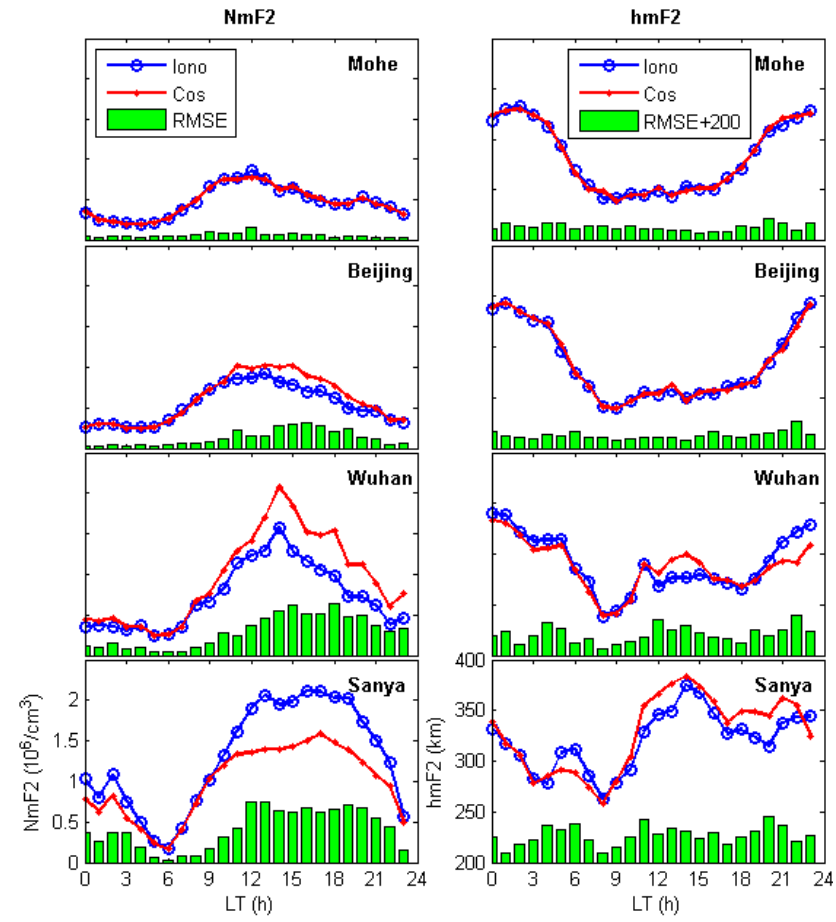

Figure 3. Comparison of diurnal variations of ionospheric parameters $N m \mathrm{~F} 2$ (left panels) and $h m \mathrm{~F} 2$ (right panels) from COSMIC and ionosonde measurements for different stations. The blue circle, red dot and green bar stand for parameters from ionosondes ("Iono") and COSMIC satellite ("Cos") and the RMSE between them. Note that a bias of 200 is added to the RMSE of $h m \mathrm{~F} 2 \mathrm{~s}$ in the right-hand panels.

local dawn (04:00-06:00 LT) and then start to increase in the morning until reaching the maximum around noontime (12:00-14:00 LT). The $N m \mathrm{~F} 2$ peak is very sharp at 14:00 LT at Wuhan, while the $N m \mathrm{~F} 2$ maintains a very high level during the whole afternoon at Sanya.

However, a difference in the ionospheric peak density from both measurements could be observed, which varies with latitude and local time. COSMIC $N m \mathrm{~F} 2$ agrees very well with that of the ionosonde at Mohe. The RMSEs of $N m$ F2s in most hours are less than $0.1 \times 10^{6} \mathrm{~cm}^{-3}$. At Beijing, the COSMIC $N m \mathrm{~F} 2$ slightly overestimates that of the ionosonde between 10:00 and 21:00 LT. The RMSEs of $N m \mathrm{~F} 2 \mathrm{~s}$ are larger than those at Mohe during this period. At Wuhan, the COSMIC NmF2 overestimates that of the ionosonde, with much higher RMSE and longer duration (08:00-23:00 LT). In contrast to the overestimation at higher latitude, COSMIC $N m \mathrm{~F} 2$ tends to underestimate that of the ionosonde in most hours at Sanya except for during 05:00-09:00 LT. The RMSE of $N m$ F2s can be as high as $0.5 \times 10^{6} \mathrm{~cm}^{-3}$ during 12:00-21:00 LT.

Regarding ionospheric peak height, the hourly averaged $h m \mathrm{~F} 2 \mathrm{~s}$ from both measurements show the same tendency in diurnal variation. COSMIC $h m \mathrm{~F} 2$ agrees well with that of the 
ionosonde at midlatitude stations (Mohe and Beijing), with an RMSE of $h m \mathrm{~F} 2 \mathrm{~s}$ that is less than $30 \mathrm{~km}$ in each hour. The $h m \mathrm{~F} 2$ decreases at dawn and maintains a low level at about $250 \mathrm{~km}$ during the daytime. In the evening, the $h m \mathrm{~F} 2$ starts to enhance and reaches its maximum around midnight. Unlike the $h m \mathrm{~F} 2$ at midlatitude stations, which remains steady during the daytime, the $h m \mathrm{~F} 2$ at low-latitude stations (Wuhan and Sanya) exhibits another peak at 14:00 LT. The daytime peak is even greater than the nighttime one at Sanya. In addition, the differences between COSMIC $h m \mathrm{~F} 2$ and ionosonde $h m \mathrm{~F} 2$ at low-latitude stations are much larger than at midlatitude stations. The COSMIC $h m F 2$ either overestimates or underestimates that of the ionosonde in most hours. For example, the COSMIC $h m \mathrm{~F} 2$ underestimates the ionosonde $h m \mathrm{~F} 2$ during 21:00-23:00 LT (04:00-06:00 LT) at Wuhan (Sanya), while it overestimates the ionosonde $h m \mathrm{~F} 2$ during 12:0015:00 LT (11:00-22:00 LT) at Wuhan (Sanya). The RMSEs of $h m \mathrm{~F} 2 \mathrm{~s}$ are also higher than those at Mohe and Beijing in most hours.

Figure 4 displays the absolute and relative errors between COSMIC and ionosonde $N m F 2 s$ at four stations. It can be seen that the absolute and relative errors in $N m \mathrm{~F} 2$ s vary with latitude. The RMSE and mean | relative error $\mid$ of $N m \mathrm{~F} 2 \mathrm{~s}$ and $h m \mathrm{~F} 2 \mathrm{~s}$ are also provided. Because the relative errors are of sign, the mean | relative error $\mid$ is averaged from the absolute value of relative errors in order to avoid the neutralization effect. At Mohe and Beijing the errors of $\mathrm{NmF} 2 \mathrm{~s}$ are very slight. The absolute and relative errors are distributed nearly symmetrically around 0 . Most of the absolute and relative errors of $N m \mathrm{~F} 2 \mathrm{~s}$ are within $-0.3 \times 10^{6}$ to $0.3 \times 10^{6} \mathrm{~cm}^{-3}$ and -30 to $30 \%$, respectively. The overall RMSEs of $N m \mathrm{~F} 2 \mathrm{~s}$ are $0.06 \times 10^{6}$ and $0.17 \times 10^{6} \mathrm{~cm}^{-3}$ for Mohe and Beijing. The corresponding mean | relative errors $\mid$ of $N m \mathrm{~F} 2 \mathrm{~s}$ are $11.4 \%$ and $16.7 \%$. At Wuhan, the absolute and relative errors of $N m \mathrm{~F} 2 \mathrm{~s}$ are mostly positive, which indicates the overestimation of $N m \mathrm{~F} 2$. The corresponding RMSE and mean | relative errors $\mid$ of $N m \mathrm{~F} 2 \mathrm{~s}$ are $0.36 \times 10^{6} \mathrm{~cm}^{-3}$ and $38.9 \%$. In contrast, most of the absolute and relative errors of $N m \mathrm{~F} 2 \mathrm{~s}$ are negative at Sanya, which represents the underestimation condition. The corresponding RMSE and mean | relative errors | of $N m \mathrm{~F} 2 \mathrm{~s}$ are $0.51 \times 10^{6} \mathrm{~cm}^{-3}$ and $23.8 \%$. It is interesting to note that, although the RMSE of $N m \mathrm{~F} 2 \mathrm{~s}$ is larger at Sanya than at Wuhan, the mean | relative errors $\mid$ is smaller at Sanya than at Wuhan. This discrepancy is caused by the difference in background $N m \mathrm{~F} 2 \mathrm{~s}$ at these two stations: since the $N m \mathrm{~F} 2$ measured by ionosonde at Wuhan is usually much smaller than that at Sanya. For example, the averaged $N m \mathrm{~F} 2 \mathrm{~s}$ from ionosonde measurements are 1.30 and $1.99 \times 10^{6} \mathrm{~cm}^{-3}$ at Wuhan and Sanya, respectively, during the period of 12:0014:00 LT for the selected data sets.

Regarding the absolute and relative errors between COSMIC and ionosonde $h m \mathrm{~F} 2 s$ presented in Fig. 5, it can be found that the errors of $h m \mathrm{~F} 2 \mathrm{~s}$ are quite small at all stations. Both the absolute and relative errors are distributed in a similar symmetric pattern, without distinct underestimation
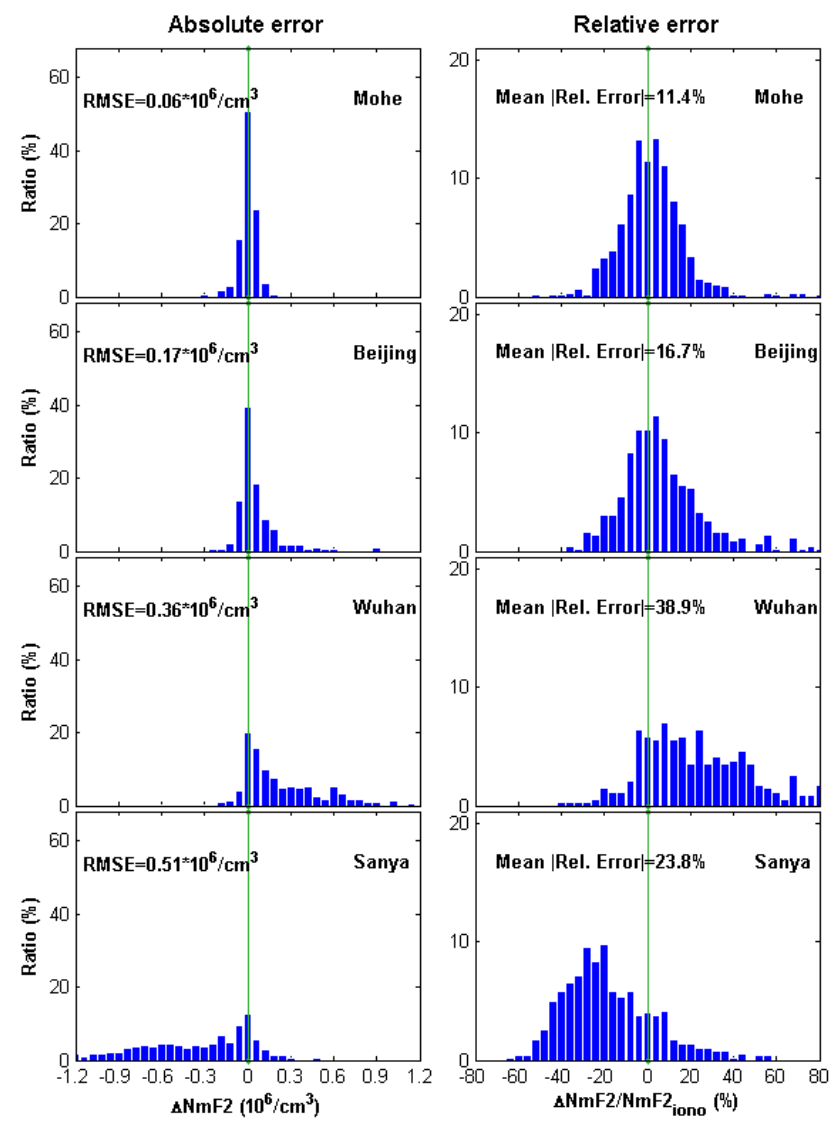

Figure 4. Absolute and relative errors of $\mathrm{NmF} 2 \mathrm{~s}$ from COSMIC and ionosonde measurements.

or overestimation. However, slight difference can still be found between stations. The RMSEs of $h m \mathrm{~F} 2 \mathrm{~s}$ are smaller at midlatitude stations ( $13 \mathrm{~km}$ at Mohe and Beijing) and larger at low-latitude stations $(22 \mathrm{~km}$ at Wuhan and $29 \mathrm{~km}$ at Sanya). The mean | relative errors $\mid$ are about $3 \%$ at midlatitude stations (Mohe, Beijing), while they are greater than $5 \%$ at low-latitude station (Wuhan and Sanya).

Figures 6 and 7 show the RMSE of $N m \mathrm{~F} 2 \mathrm{~s}$ and $h m \mathrm{~F} 2 \mathrm{~s}$ from COSMIC and ionosonde measurements in different local times and seasons. May to August and November to February are denoted as summer and winter, respectively, and March to April and September to October are denoted as the equinox period. It could be found that the RMSEs of $N m \mathrm{~F} 2 \mathrm{~s}$ and $h m \mathrm{~F} 2 \mathrm{~s}$ increase with decreasing latitude. The RMSE of $N m \mathrm{~F} 2 \mathrm{~s}$ is higher during the daytime than during the nighttime at all stations. In contrast, the RMSE of $h m \mathrm{~F} 2 \mathrm{~s}$ is slightly lower during the daytime than during the nighttime. Regarding the seasonal variation, the RMSE of $N m \mathrm{~F} 2 \mathrm{~s}$ is lowest in summer for all stations and highest in the equinox period at Beijing, Wuhan and Sanya. The seasonal variation of the RMSE of $h m F 2$ differs greatly between low- and midlatitude stations. The RMSE of $h m F 2 s$ is lowest in the 

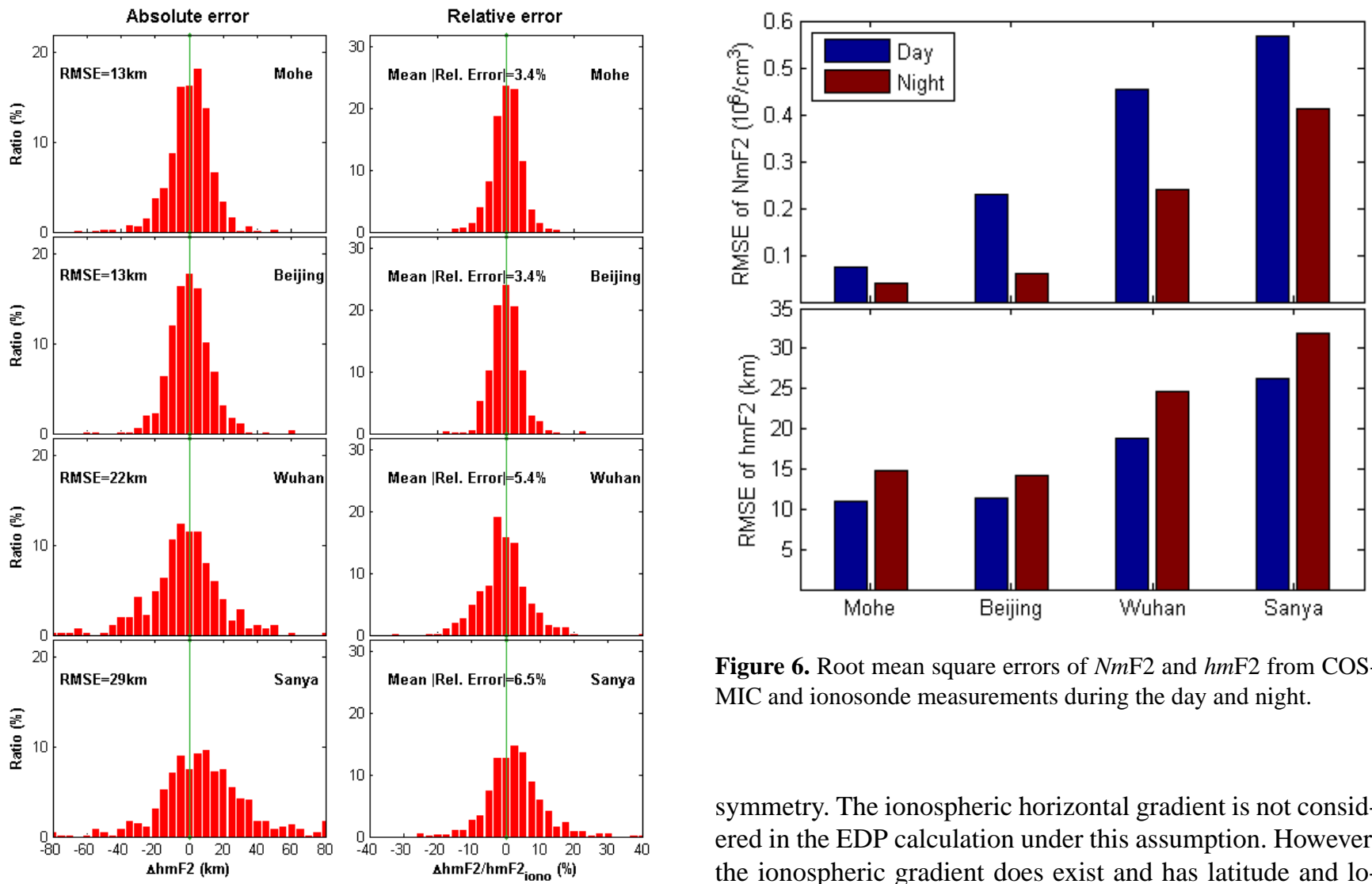

Figure 6. Root mean square errors of $N m \mathrm{~F} 2$ and $h m \mathrm{~F} 2$ from COS$\mathrm{MIC}$ and ionosonde measurements during the day and night.

Figure 5. The same as Fig. 4 but for $h m \mathrm{~F} 2 \mathrm{~s}$.

equinox period at Mohe and Beijing, while it is highest in the equinox period and lowest in summer at Wuhan and Sanya.

Figure 8 presents the scatterplots of $N m \mathrm{~F} 2 \mathrm{~s}$ and $h m \mathrm{~F} 2 \mathrm{~s}$ retrieved from COSMIC and ionosonde measurements. The sample numbers and correlation coefficients are also displayed. The correlations of $N m \mathrm{~F} 2 \mathrm{~s}$ between COSMIC and ionosondes are considerable. The correlation coefficients decrease with latitude from 0.97 at Mohe to 0.90 at Sanya. Comparing the scatter dots with the diagonal line $(y=x)$, the overestimation of $N m \mathrm{~F} 2$ at Wuhan and underestimation at Sanya are distinctive. The correlations of $h m \mathrm{~F} 2 \mathrm{~s}$ at Mohe and Beijing are much higher than those at Wuhan and Sanya, and no evident underestimation or overestimation is found. Regarding the difference in the correlation of $\mathrm{NmF} 2 \mathrm{~s}$ and $h m \mathrm{~F} 2 \mathrm{~s}$, the correlations of both parameters are comparatively high at Mohe and Beijing. However, the correlations of $N m \mathrm{~F} 2 \mathrm{~s}$ are much higher than those of $h m \mathrm{~F} 2 \mathrm{~s}$ at Wuhan and Sanya, which are closer to the equatorial ionization anomaly (EIA) region.

\section{Discussion}

The most critical assumption during the retrieval of ionospheric EDP from RO measurement is the global ionospheric 


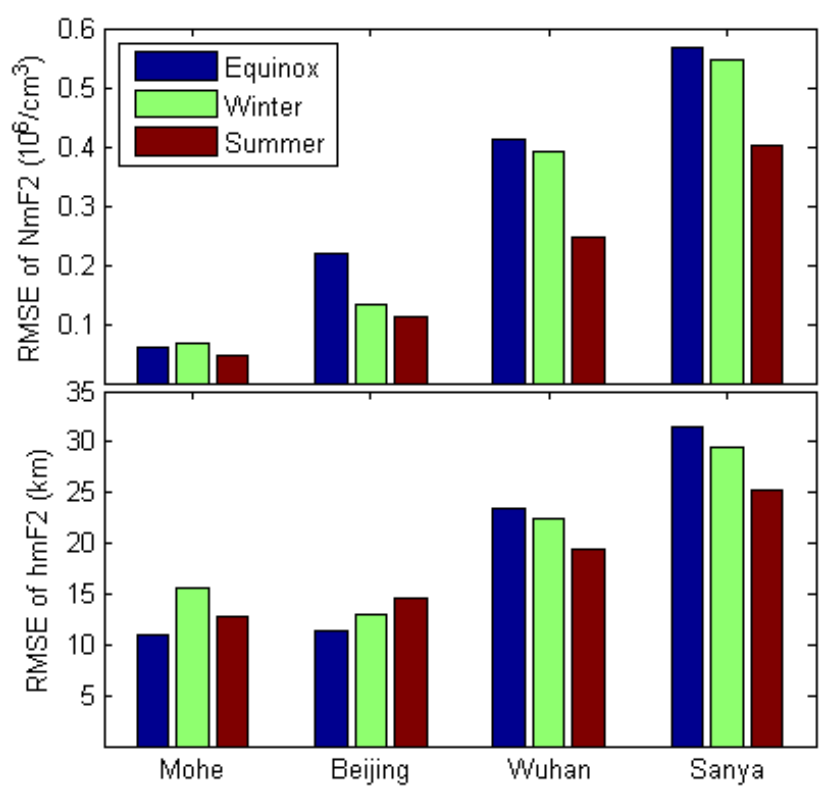

Figure 7. Root mean square errors of $N m \mathrm{~F} 2$ and $h m \mathrm{~F} 2$ from COSMIC and ionosonde measurements in the equinox, winter and summer periods.

et al., 2010). The errors of ionospheric parameters are more significant in low-latitude regions and between noontime and sunrise (Yue et al., 2011a). The latitudinal distribution of the estimation error can be explained by the spherical symmetry assumption. When the tangent points are in the EIA crest regions, electron densities are underestimated because the real slant TEC does not support high values in that spherical layer. In the nearby region the electron density will be overestimated because the effects of the EIA peak region are spread by the inversion under the spherical symmetry assumption (Yue et al., 2010).

Our comparison also shows overestimation and underestimation of $N m \mathrm{~F} 2$ at stations with different latitudes. But the areas of overestimation/underestimation are slightly different from those in the simulation results of Yue et al. (2010). For example, Wuhan and Sanya are located at areas of "underestimation" and "overestimation" according to the model results, but contrary results are presented by current ground-based comparison. The discrepancy may result from the deviation between $f o \mathrm{~F} 2 \mathrm{~s}$ from NeQuick calculation and ionosonde observation. $\mathrm{Lu}$ and Liu (2008) evaluated the prediction ability of NeQuick model on $f o \mathrm{~F} 2$ over Asia-Australia sector. Their results indicate that the foF 2 from NeQuick model overestimates/underestimates that from ionosonde observation in most hours at Wuhan and Taipei $\left(121.5^{\circ} \mathrm{E}, 25.0^{\circ} \mathrm{N}\right.$ ) (see Fig. 1 of the reference). The discrepancy may also result from the seasonal and solar cycle variation of the EIA. As pointed out by Huang and Chen (1996), the strength and the latitude position of the most developed EIA have a seasonal and solar cycle
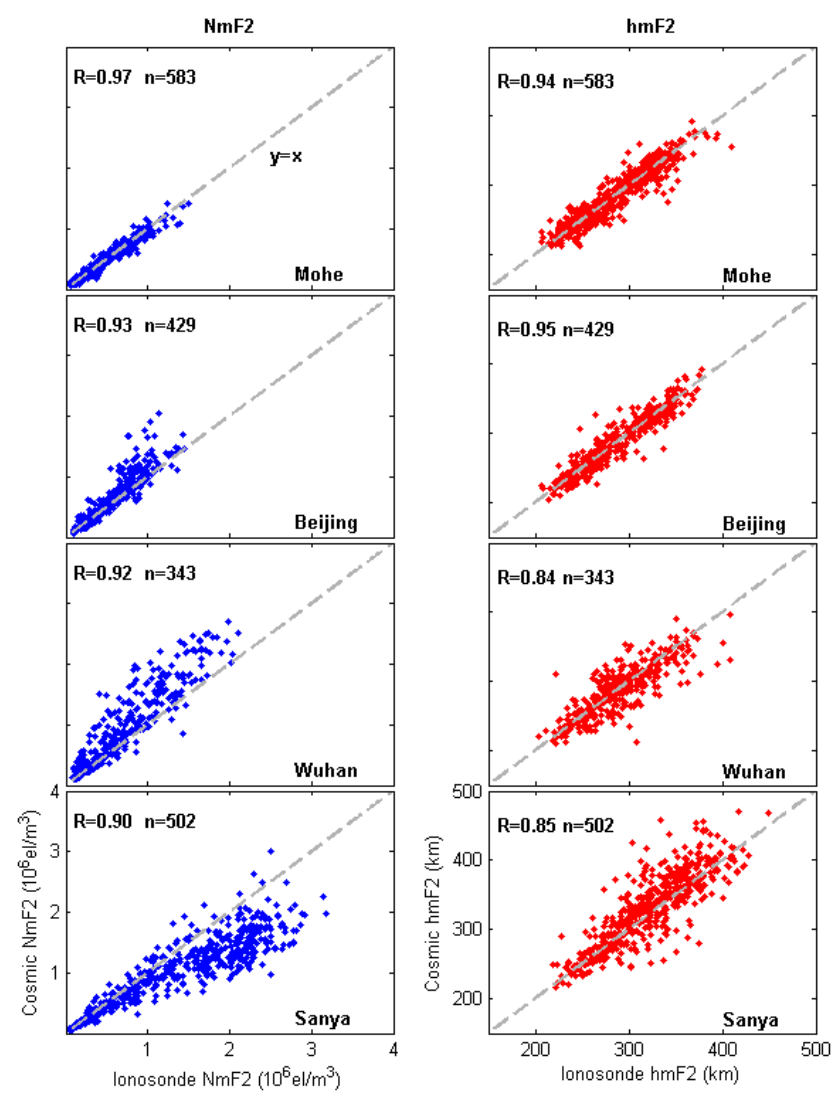

Figure 8. Scatterplots of COSMIC and ionosonde-based $\mathrm{NmF} 2 \mathrm{~s}$ (left panels) and $h m \mathrm{~F} 2 \mathrm{~s}$ (right panels). The correlation coefficients $(R)$ and number of data pairs $(n)$ are also provided. The diagonal line represents the $(y=x)$ function.

dependency. The winter crest appears larger and is earlier than the summer crest, and the summer crest appears at a lower latitude than that of other seasons. The latitudinal variation of absolute deviation between COSMICretrieved and NeQuick-calculated electron density was simulated from globally distributed RO events during the daytime (12:00-14:00 LT) of the spring equinox during solar minimum (2008) (Yue et al., 2010). However, our comparison is based on ionosonde observations in all seasons and all the local time during solar maximum (2011-2013) along the $120^{\circ} \mathrm{E}$ longitude. The difference in the period and spatial coverage of data may lead to the difference in position and strength of the EIA. It is reasonable to expect the underestimation and overestimation of $N m \mathrm{~F} 2$ at Sanya and Wuhan if the position of the EIA moves towards the lower latitude. However, the correlation between the deviation of electron density and the presence, strength and position of the EIA is beyond the scope of this paper. It will be investigated in future work.

Our results are also slightly different from the global survey of COSMIC ionospheric peak parameters by Chu et al. (2010). Their results show that the mean values of 
peak electron density measured by COSMIC satellites are systematically smaller than those observed by ionosondes, while the COSMIC-measured peak height is systematically higher than the ionosonde derived $h m \mathrm{~F} 2$. The COSMIC $N m \mathrm{~F} 2 \mathrm{~s}$ are larger than those of ionosondes in high-latitude $\left(>60^{\circ}\right.$ ) regions by about $10-30 \%$ and smaller in lowlatitude and equatorial regions by less than $10 \%$. The COSMIC $h m \mathrm{~F} 2 \mathrm{~s}$ are higher than those of ionosondes by about $0-15 \%$ in high-latitude region and $10-25 \%$ in low-latitude and equatorial regions (Chu et al., 2010). However, no evident overestimation of $h m \mathrm{~F} 2$ is shown in our results. The difference may result from the data source and method of data processing. The data used by Chu et al. (2010) were collected from inhomogeneously distributed stations during a period of 8 months during solar minimum (July 2006 to February 2007), while the data used in this analysis are from the ionosonde observation chain in China during the solar maximum of 2011-2013. Since the ionospheric gradient is dependent on locations and solar activity, the difference in data period and station distribution may lead to the discrepancy in the comparison results. In addition, the ionosonde $h m \mathrm{~F} 2$ employed in the research of Chu et al. (2010) was directly obtained from SWPC, which was estimated from the virtual heights based on the POLynomial ANalysis (POLAN) method. However, the ionosonde $h m \mathrm{~F} 2 \mathrm{~s}$ involved in this research are calculated by the NHPC algorithm after all the ionograms are manually scaled. As reported by Šauli et al. (2007), there are significant systematic differences between electron density profiles calculated by POLAN and NHPC inversion methods. The reflection true height for a given frequency computed by NHPC is systematically higher in nighttime profiles. By contrast, the reflection true height for a given frequency computed by POLAN in daytime profiles is higher, and the standard mean deviation representing the significance of the result is smaller especially in twolayer profiles.

Error analysis shows that the error in $N m \mathrm{~F} 2 \mathrm{~s}$ varies significantly with the latitude (Fig. 4). However, the latitudinal dependency of the error in $h m \mathrm{~F} 2 \mathrm{~s}$ is not so distinct (Fig. 5). Neither underestimation nor overestimation is evident in the absolute or relative error in $h m \mathrm{~F} 2 \mathrm{~s}$ at four stations. In addition, the mean | relative error $\mid$ of $h m \mathrm{~F} 2 \mathrm{~s}$ is much smaller than that of $N m \mathrm{~F} 2 \mathrm{~s}$ at each station. All these results indicate that the retrieval algorithm of COSMIC EDP performs better when determining the ionospheric peak height than when determining the peak density. Similar results have been reported by simulation and ionosonde validation. The standard deviation of the relative retrieval error is $\sim 15 \%$ for $N m \mathrm{~F} 2$ and $\sim 2 \%$ for $h m \mathrm{~F} 2$ on the basis of 43180 COSMIC occultation events simulated during the spring equinox of 2008 (Yue et al., 2010). The relative standard deviations of $N m \mathrm{~F} 2$ and $h m \mathrm{~F} 2$ are 8.4 and $4.9 \%$ obtained by comparing the profiles from COSMIC with those from the Pruhonice and Juliusruh ionosondes in Europe during 2008 (Krankowski et al., 2011).
Scatterplots show high correlations between ionospheric peak parameters from COSMIC and ionosonde measurements (Fig. 8). At midlatitude stations (Mohe and Beijing), the correlations of both $N m \mathrm{~F} 2 \mathrm{~s}$ and $h m \mathrm{~F} 2 \mathrm{~s}$ are greater than 0.9. High correlations of $N m \mathrm{~F} 2 \mathrm{~s}(0.99)$ and $h m \mathrm{~F} 2 \mathrm{~s}(0.95)$ are also reported by Krankowski et al. (2011) in a similar latitude region. At low-latitude stations (Wuhan and Sanya), the correlations of $\mathrm{NmF} 2 \mathrm{~s}$ are higher than those of $h m$ F2s. Some correlation analysis between COSMIC and ionosonde measurements have been conducted at different locations in low-latitude regions. Comparisons at Jicamarca during the solar minimum of 2006-2008 show high correlations between the two types of measurements, with correlations greater than 0.9 and 0.8 for $N m \mathrm{~F} 2$ and $h m \mathrm{~F} 2$, respectively (J.-Y. Liu et al., 2010; Chuo et al., 2011). Comparison of characteristics of ionospheric parameters obtained from COSMIC and a digisonde over Ascension Island also illustrates similar diurnal variation and high correlation for both $N m \mathrm{~F} 2(>0.91)$ and $h m \mathrm{~F} 2(>0.72)$ in the equinox, summer and winter periods (Chuo et al., 2013). Comparison between RO EDPs from the COSMIC satellites with digisonde data over the Brazilian region shows generally good correlation for $N m$ F2 (0.92) and $h m F 2$ (0.78) (Ely et al., 2012). In addition, all the mentioned comparisons unanimously show higher correlation for $N m \mathrm{~F} 2$ than for $h m \mathrm{~F} 2$.

\section{Summary}

The COSMIC ionospheric peak parameters $(\mathrm{NmF} 2$ and $h m \mathrm{~F} 2$ ) over China are validated by the ionosonde data from an observation chain which consists of four stations during 2011-2013. The diurnal variation, absolute and relative errors, and correlations of the $N m \mathrm{~F} 2$ and $h m \mathrm{~F} 2$ from COSMIC and ionosonde measurements are analyzed. It is the first validation of latitudinal variation by manually scaled ionosonde data, which provides a reference for ionospheric research based on the Abel-retrieved EDPs, especially the one relating to different latitude regions. The results are as follow:

1. Comparison results show that the COSMIC measurement generally agrees well with ionosonde observations during the solar maximum period. The diurnal variations of $N m \mathrm{~F} 2$ and $h m \mathrm{~F} 2$ from the COSMIC measurement follow the same trend as those from ionosonde observations.

2. The COSMIC NmF2 has evident latitudinal dependency. It differs slightly from the ionosonde $N m \mathrm{~F} 2$ at midlatitude stations but overestimates and underestimates the ionosonde $N m \mathrm{~F} 2$ in the north (Wuhan) and south (Sanya) of the EIA crest.

3. The relative error in $h m \mathrm{~F} 2 \mathrm{~s}$ is much less than that of $N m \mathrm{~F} 2 \mathrm{~s}$, which indicates that the COSMIC data retrieval algorithm performs better when determining the 
ionospheric peak height than when determining the peak density.

4. The RMSEs of $N m \mathrm{~F} 2 \mathrm{~s}$ are lower during the nighttime and in summer, while the RMSEs of $h m \mathrm{~F} 2 \mathrm{~s}$ are higher during nighttime for all stations.

5. The correlation of $N m \mathrm{~F} 2 \mathrm{~s}$ decreases with latitude. At midlatitude stations, the correlation of $N m \mathrm{~F} 2 \mathrm{~s}$ and $h m \mathrm{~F} 2 \mathrm{~s}$ is the same. At low-latitude stations, the correlation of $N m \mathrm{~F} 2 \mathrm{~s}$ is higher than that of $h m \mathrm{~F} 2 \mathrm{~s}$.

Acknowledgements. We acknowledge the use of ionosonde data from the Chinese Meridian Project and COSMIC data from CDAAC. This research was supported by the National Natural Science Foundation of China (41204113, 41104106, 41127003, 41374164), the Chinese Academy of Sciences project (KZZDEW-01-3), National Key Basic Research Program of China (2012CB825604) and the National Science and Technology Basic Work Program (2008FY120100).

Topical Editor J. Wild thanks two anonymous referees for their help in evaluating this paper.

\section{References}

Cherniak, Iu. V. and Zakharenkova, I.: Validation of FORMOSAT3/COSMIC radio occultation electron density profiles by incoherent scatter radar data, Adv. Space Res., 53, 1304-1312, doi:10.1016/j.asr.2014.02.010, 2014.

Chu, Y.-H., Su, C.-L., and Ko, H.-T.: A global survey of COSMIC ionospheric peak electron density and its height: A comparison with ground-based ionosonde measurements, Adv. Space Res., 46, 431-439, doi:10.1016/j.asr.2009.10.014, 2010.

Chuo, Y.-J., Lee, C.-C., Chen, W.-S., and Reinisch, B. W.: Comparison between bottomside ionospheric profile parameters retrieved from FORMASAT3 measurements and ground-based observations collected at Jicamarca, J. Atmos. Sol.-Terr. Phy., 73, 16651673, doi:10.1016/j.jastp.2011.02.021, 2011.

Chuo, Y. J., Lee, C. C., Chen, W. S., and Reinisch, B. W.: Comparison of the characteristics of ionospheric parameters obtained from FORMOSAT-3 and digisonde over Ascension Island, Ann. Geophys., 31, 787-794, doi:10.5194/angeo-31-787-2013, 2013.

Ely, C. V., Batista, I. S., and Abdu, M. A.: Radio occultation electron density profiles from the FORMASAT-3/COSMIC satellites over the Brazilian region: A comparison with Digisonde data, Adv. Space Res., 49, 1553-1562, doi:10.1016/j.asr.2011.12.029, 2012.

Galkin, I. A. and Reinisch, B. W.: The new ARTIST 5 for all digisondes, INAG Bulletin 69, 2008.

Hajj, G. A. and Romans, L. J.: Ionospheric electron density profiles obtained with the Global Positioning System: Results from the GPS/MET experiment, Radio Sci., 33, 175-190, 1998.

Hu, L., Ning, B., Liu, L., Zhao, B., Chen, Y., and Li, G.: Comparison between ionospheric peak parameters retrieved from COSMIC measurement and ionosonde observation over Sanya, Adv. Space Res., 54, 929-938, doi:10.1016/j.asr.2014.05.012, 2014.
Huang, Y.-N., and Cheng, K.: Solar cycle variations of the equatorial ionospheric anomaly in total electron content in the Asian region, J. Geophys. Res., 101, 24513-24520, doi:10.1029/96JA01297, 1996.

Kelley, M. C., Wong, V. K., Aponte, N., Coker, C., Mannucci, A. J., and Komjathy, A.: Comparison of COSMIC occultationbased electron density profiles and TIP observations with Arecibo incoherent scatter radar data, Radio Sci., 44, RS4011, doi:10.1029/2008RS004087, 2009.

Krankowski, A., Zakharenkova, I., Krypiak-Gregorczyk, A., Shagimuratov, I., and Wielgosz, P.: Ionospheric electron density observed by FORMOSAT-3/COSMIC over the European region and validated by ionosonde data, J. Geodesy, 85, 949-964, doi:10.1007/s00190-011-0481-z, 2011.

Lei, J., Syndergaard, S., Burns, A. G., Solomon, S. C., Wang, W., Zhen, Z., Roble, R. G., Wu, Q., Kuo, Y.-H., Holt, J. M., Zhang, S.-R., Hysell, D. L., Rodrigues, F. S., and Lin, C.-H.: Comparison of COSMIC ionospheric measurements with ground-based observations and model predictions: Preliminary results, J. Geophys. Res., 112, A07308, doi:10.1029/2006JA012240, 2007.

Liu, J.-Y., Lee, C.-C., Yang, J.-Y., Chen, C.-Y., and Reinisch, B. W.: Electron density profiles in the equatorial ionosphere observed by the FORMASAT-3/COSMIC and a digisonde at Jicamarca, GPS Solut, 14, 75-81, doi:10.1007/s10291-009-0150-3, 2010.

Liu, L., Wan, W., Zhang, M.-L., Ning, B., Zhang, S.-R., and Holt, J. M.: Variations of topside ionospheric scale heights over Millstone Hill during the 30-day incoherent scatter radar experiment, Ann. Geophys., 25, 2019-2027, doi:10.5194/angeo-252019-2007, 2007.

Liu, L., He, M., Wan, W., and Zhang, M.-L.: Topside ionospheric scale heights retrieved from Constellation Observing System for Meteorology, Ionosphere, and Climate radio occultation measurements, J. Geophys. Res., 113, A10304, doi:10.1029/2008JA013490, 2008.

Liu, L., Zhao, B., Wan, W., Ning, B., Zhang, M.-L., and He, M.: Seasonal variations of the ionospheric electron densities retrieved from Constellation Observing System for Meteorology, Ionosphere, and Climate mission radio occultation measurements, J. Geophys. Res., 114, A02032, doi:10.1029/2008JA013819, 2009.

Liu, L., Wan, W., Ning, B., Zhang, M.-L., He, M., and Yue, X.: Longitudinal behaviors of the IRI-B parameters of the equatorial electron density profiles retrieved from FORMOSAT-3/COSMIC radio occultation measurements, Adv. Space Res., 46, 1064 1069, doi:10.1016/j.asr.2010.06.005, 2010.

Liu, L., Le, H., Chen, Y., He, M., Wan, W., and Yue, X.: Features of the middle and low latitude ionosphere during solar minimum as revealed from COSMIC radio occultation measurements, J. Geophys. Res., 116, A0930, doi:10.1029/2011JA016691, 2011.

Lu, L. and Liu, L.: Evaluation of the prediction ability of the NeQuick model on $f o F 2$ over Asia-Australia sector, Chin. J. Space Sci., 28, 222-229, 2008.

Reinisch, B. W. and Galkin, I. A.: Global Ionospheric Radio Observatory (GIRO), Earth Planets Space, 63, 377-381, 2011.

Reinisch, B. W. and Huang, X.: Deducing topside profiles and total electron content from bottomside ionograms, Adv. Space Res., 27, 23-30, 2001.

Rocken, C., Kuo, Y.-H., Schreiner, W., Hunt, D., Sokolovskiy, S., and McCormick, C.: COSMIC system description, Terr. Atmos. Ocean. Sci., 11, 21-52, 2000. 
Šauli, P., Mošna, Z., Boška, J., Kouba, D., Laštovička, J., and Altadill, D.: Comparison of true-height electron density profiles derived by POLAN and NHPC methods, Stud. Geophys. Geod., 51, 449-459, doi:10.1007/s11200-007-0026-3, 2007.

Schreiner, W. S., Sokolovskiy, S. V., Rocken, C., and Hunt, D. C.: Analysis and validation of GPS/MET data in the ionosphere, Radio Sci., 34, 949-966, 1999.

Wickert, J., Michalak, G., Schmidt, T., Beyerle, G., Cheng, C.-Z., Healy, S. B., Heise, S., Huang, C.-Y., Jakowski, N., Köhler, N., Mayer, C., Offiler, D., Zawa, E., Pavelyev, A. G., Rothacher, M., Tapley, B., and Arras, C.: GPS Radio Occultation: Results from CHAMP, GRACE and FORMASAT-3/COSMIC, Terr. Atmos. Ocean. Sci., 20, 35-50, 2009.

Yue, X., Schreiner, W. S., Lei, J., Sokolovskiy, S. V., Rocken, C., Hunt, D. C., and Kuo, Y.-H.: Error analysis of Abel retrieved electron density profiles from radio occultation measurements, Ann. Geophys., 28, 217-222, doi:10.5194/angeo-28-217-2010, 2010.
Yue, X., Schreiner, W. S., Rocken, C., and Kuo, Y.-H.: Evaluation of the orbit altitude electron density estimation and its effect on the Abel inversion from radio occultation measurements, Radio Sci., 46, RS1013, doi:10.1029/2010RS004514, 2011 a.

Yue, X., Schreiner, W. S., Lin, Y.-C., Rocken, C., Kuo, Y.-H., and Zhao, B.: Data assimilation retrieval of electron density profiles from radio occultation measurements, J. Geophys. Res., 116, A03317, doi:10.1029/2010JA015980, 2011b.

Zakharenkova, I., Krankowski, A., Shagimuratov, I., Cherniak, Y. V., Krypiak-Gregorczyk, A., Wielgosz, P., and Lagovsky, A. F.: Observation of the ionospheric strom of October 11, 2008 using FORMOSAT-3/COSMIC data, Earth Planets Space, 64, 505512, 2012.

Zhao, B., Wan, W., Yue, X., Liu, L., Ren, Z., He, M., and Liu, J.: Global characteristics of occurrence of an additional layer in the ionosphere observed by COSMIC/FORMOSAT-3, Geophys. Res. Lett., 38, L02101, doi:10.1029/2010GL045744, 2011. 